\title{
Non-steroidal anti-inflammatory drugs (NSAIDs)
}

Clarification-The original version of this Practice article by Day and Graham (BMJ 2013;346:f3195, doi:10.1136/bmj.f3195) was published on 11 June before final amendments had been made, and removed from bmj.com the following day. The present version is correct.
Cite this as: BMJ 2013;346:44310

๑ BMJ Publishing Group Ltd 2013 